\title{
Estudo comparativo da carbonização de resíduos agrícolas e florestais visando à substituição da lenha no processo de secagem de grãos de café ${ }^{1}$
}

\author{
Osmir Sater ${ }^{2}$, Natalia Dias de Souza ${ }^{3}$ Eva Adriana Gonçalves de Oliveira 4 , \\ Tatiana de Felice Elias ${ }^{5}$, Rafael Tavares ${ }^{6}$
}

\begin{abstract}
RESUMO
Este trabalho visou a comparar o potencial energético de resíduos produzidos no beneficiamento de grãos de café (Coffea canephora var. Conilon) e no processo de fresamento da madeira, sugerindo seu uso em substituição ao da lenha de eucalipto, no processo de secagem de grãos de café. O uso destes resíduos agrícola e florestal pode contribuir para a redução de problemas ambientais relacionados com a contaminação do solo, ar e água, devidos a seu descarte inadequado, e para reduzir os custos de produção e, ou, beneficiamento do café. Os subprodutos da destilação seca e o carvão vegetal dessas matérias-primas foram quantificados e comparados. De acordo com os resultados, pôde-se verificar que os resíduos de casca de café proporcionaram uma boa produção de carvão vegetal, visto que seu rendimento gravimétrico em carvão foi estatisticamente superior ao da lenha. Considerando a produtividade e qualidade do carvão vegetal, o melhor resultado foi obtido pela carbonização da casca de café nas temperaturas de $350{ }^{\circ} \mathrm{C}$ a 550 ${ }^{\circ} \mathrm{C}$ e dos resíduos da fresa de madeira a $550{ }^{\circ} \mathrm{C}$, principalmente, graças aos rendimentos médios em carbono fixo, que, nesses casos, superaram aqueles apresentados pelos carvões derivados de lenha do eucalipto. Em se tratando do poder calorífico superior, verificou-se que os resíduos da fresa de madeira e os resíduos de casca de café poderão ser utilizados para secagem de grãos de café, visto que apresentaram valores de poder calorífico superior (PCS) muito próximo aos de lenha de eucalipto. Graças aos bons rendimentos gravimétricos e rendimentos em carbono fixo, os carvões vegetais derivados dos resíduos produzidos no beneficiamento de grãos de café e no processo de fresamento da madeira apresentaram potencial considerável para serem utilizados como insumo energético.
\end{abstract}

Palavras-chave: Resíduos lignocelulósicos, pirólise, carvão vegetal.

\section{ABSTRACT}

\section{Comparative study of agricultural carbonization and forest residues in order to substitute firewood in the process of drying coffee beans}

The present work aimed to compare the energy potential of residues generated in the processing of coffee beans (Coffea canephora Pierre ex A. Froehner, var. Conilon) and in the wood milling process, suggesting their use as a replacement for eucalyptus firewood in the drying process of coffee beans. The use of agricultural and forestry waste could help reduce environmental problems related to contamination of soil, air and water due to inadequate disposal, and reduce the cost of production and or processing of coffee. By-products of dry distillation and charcoal of these raw materials were quantified and compared. According to the results, it was verified that the residue of coffee hulls

\footnotetext{
Received 20/0102011 and accepted for publication 08/11/2011

${ }^{1}$ Parte da monografia do primeiro autor.

2 Engenheiro-Florestal. Departamento de Produtos Florestais, Instituto de Florestas, Universidade Federal Rural do Rio de Janeiro, Rod. BR 465, Km 07, 23890-000, Seropédica, Rio de Janeiro, Brasil. osmirsaiter@hotmail.com

${ }_{3}^{3}$ Engenheira-Florestal, Mestre. Departamento de Produtos Florestais, Instituto de Florestas, Universidade Federal Rural do Rio de Janeiro, Rod. BR 465, Km 07, 23890-000, Seropédica, Rio de Janeiro, Brasil. natdias@ufrrj.br (autora para correspondência)

${ }^{4}$ Engenheira-Agrônoma, Mestre. Embrapa Agrobiologia, Fazendinha Agroecológica do Km 47, Rod. BR 465, Km 47, 23890-000, Seropédica, Rio de Janeiro, Brasil. evadrya @ hotmail.com.br

${ }^{5}$ Engenheira-Agrônoma, Doutora. Departamento de Produtos Florestais, Instituto de Florestas, Universidade Federal Rural do Rio de Janeiro, Rod. BR 465, Km 07, 23890-000, Seropédica, Rio de Janeiro, Brasil. tatifelice@ig.com.br

${ }^{6}$ Acadêmico do Curso de Engenharia Florestal. Departamento de Produtos Florestais, Instituto de Florestas, Universidade Federal Rural do Rio de Janeiro, Rod. BR 465, Km 07, 23890-000, Seropédica, Rio de Janeiro, Brasil.rafapoptavares@gmail.com
} 
provided an exceptional charcoal production, in which the charcoal generated was statistically predominant. Considering the yield and quality of charcoal, the best result was obtained by carbonization of coffee hulls at temperatures of $350^{\circ} \mathrm{C}$ and $550^{\circ} \mathrm{C}$ and the residues of milling at $550^{\circ} \mathrm{C}$, mainly due to average yields on fixed carbon. In such cases, these results exceeded those given by charcoal produced derived from wood of eucalyptus. In regards to the calorific value, it was found that residues from wood and coffee hulls could be used for drying coffee beans, since they have similar values to that of eucalyptus. Due to the high charcoal and fixed carbon yields, the charcoals produced from the processing of coffee beans and the wood milling process showed considerable potential for use as an energy source.

Key words: Lignocellulosic residues, pyrolysis, charcoal.

\section{INTRODUÇÃO}

O grande volume de resíduos gerados pelas indústrias de transformação da madeira e pela agricultura é, ao mesmo tempo, uma oportunidade e um desafio, em praticamente todas as regiões do Brasil.

Embora as empresas modernas incluam em suas atividades o gerenciamento ambiental e o aproveitamento integrado de seus subprodutos, a maioria das empresas ainda está despreparada para o descarte apropriado de seus rejeitos. Problemas ambientais relacionados com contaminação dos solos e lençóis freáticos, devidos ao descarte inadequado e ao acúmulo de resíduos florestais e agrícolas, podem aparecer. De modo geral, esses resíduos são queimados ou dispostos em aterros inadequados, acarretando o desprendimento de chorume, provocando danos ao ambiente, principalmente em córregos, rios e mananciais (Brand et al., 2002).

Existem várias opções para o aproveitamento dos resíduos lignocelulósicos, como exemplo pode-se citar a utilização deles como coberturas em granjas, nas indústrias de painéis de madeira reconstituída, na compostagem, na geração de energia pela queima direta, na produção de combustível sólido (carvão vegetal) ou na transformação dos resíduos em briquetes, entre outras possibilidades (Quirino, 2003). No reaproveitamento dos resíduos, como na pirólise da matéria-prima, o que era resíduo transformar-se-á em energia, ajudando, assim, na preservação da natureza e na economia de energia.

O Brasil vislumbra uma tendência estratégica do crescimento da energia proveniente da biomassa como substituta do petróleo, levando-se em conta a grande extensão do território nacional e a aptidão brasileira para a silvicultura, aliadas à possibilidade de utilização de resíduos florestais e agrícolas. Assim, os resíduos de origem florestal e agrícola formam uma categoria interessante de biomassa que pode ser explorada (Vale et al., 2007).

Considerando-se a quantidade de energia total consumida no Brasil, cerca de $47 \%$ é oriunda de fontes renováveis, enquanto a média do planeta gira em torno de 13\% (Nascimento, 2011). Em condições favoráveis, os resíduos podem contribuir de maneira significativa para a produção de energia elétrica. Hall (1991), em seus trabalhos, estimou que, com a recuperação de um terço dos resíduos disponíveis, seria possível o atendimento de $10 \%$ do consumo de energia elétrica mundial e que, com um programa de plantio de culturas, especialmente para esta atividade, em uma área de 100 milhões de hectares, seria possível atender a $30 \%$ deste consumo.

O Estado do Espírito Santo é o segundo maior produtor de café do Brasil, tendo produzido em 2009 cerca de 10,2 milhões de sacas, e o primeiro de Coffea conephora var. Conilon, com uma produção de 7,6 milhões de sacas (Conab, 2010). A produção capixaba de café representa mais de $25 \%$ do total nacional (Ferrão et al., 2007). Atualmente, quase toda essa produção é seca de forma artificial, com uso de calor, utilizando-se a lenha como fonte de energia, sendo mais utilizada a lenha de eucalipto. Entretanto, a tendência atual do planejamento integrado dos recursos energéticos exige o estudo de diferentes alternativas de fontes para a secagem de grãos. Aspectos como a minimização do impacto ambiental e a escassez de recursos não renováveis devem ser considerados na seleção das fontes de energia a serem utilizadas (Afonso Júnior $e t$ al., 2006).

Embora a parcela de terra necessária para a produção anual de lenha para secagem ser relativamente pequena, quando comparada com a área destinada à produção agrícola, variando de $0,50 \%$ para a cultura do feijão, até $4,23 \%$ para a cultura do café, é importante ressaltar a possibilidade de utilização de outras fontes alternativas de biomassa para secagem, como sabugo de milho, casca de arroz, restos culturais da renovação da lavoura de café e demais resíduos agrícolas (Afonso Júnior et al., 2006).

Em razão disso, o objetivo deste trabalho foi comparar o potencial energético de resíduos produzidos no beneficiamento de grãos de café (Coffea canephora var. Conilon) e no processo de fresamento da madeira, suge- 
rindo o seu uso em substituição ao da lenha de eucalipto, no processo de secagem de grãos de café, diminuindo, assim, os problemas ambientais relacionados com a contaminação do solo, ar e água, por meio do descarte inadequado de resíduos agrícolas e florestais e, também, reduzindo os custos de produção e, ou, beneficiamento.

\section{MATERIAL E MÉTODOS}

\section{Matérias-primas}

As matérias-primas utilizadas na condução da pesquisa constaram de resíduos do processo de beneficiamento de grãos de café (Coffea canephora var. Conilon), resíduos do processo de fresamento da madeira para a fabricação de esquadrias (espécies nativas: Maçaranbuba Manilkara elata (Allemão ex Miq.) Monach.; Freijó Cordia goeldiana Huber; Cerejeira - Amburana cearensis (Allemão) A.C. Sm.) e 10 discos da lenha de Eucalyptus grandis W. Hill com 14 anos de idade, os quais foram adotados como testemunha. Esses materiais foram provenientes do Município de Rio Bananal, no Estado do Espírito Santo. As cascas do café e os resíduos da fresa de madeira foram utilizados na sua forma de descarte; já a lenha do eucalipto foi cavaqueada para sua melhor manipulação (Figura 1).

\section{Análise termo-gravimétrica de materiais lignocelulósicos - destilação seca}

As amostras foram secas em estufa, a $105 \pm 3{ }^{\circ} \mathrm{C}$, durante 48 horas. Em seguida, foram submetidas ao processo de destilação seca, utilizando-se 120 gramas para cada repetição, tendo sido realizadas cinco repetições para cada tratamento (Tabela 1).

Depois da destilação seca, tendo por base a matéria seca pirolisada, foram determinados os rendimentos gravimétricos em carvão (RCV), os rendimentos em gases condensáveis (RGC) e em gases não condensáveis (RGI).

\section{Análise química imediata do carvão vegetal}

A análise química imediata do carvão vegetal foi efetuada com base na norma ASTM-1762 - 64, adaptada por
Oliveira et al. (1982), determinando-se os teores de materiais voláteis (TMV), cinzas (TCZ) e carbono fixo (TCF).

\section{Poder calorifico superior}

O poder calorífico superior foi estimado, aplicando-se a Fórmula de Goutal (Mendes et al., 1982), expressa pela Equação 1:

$$
P C S=(82 C f+A V)
$$

onde:

$P C S=$ Poder calorífico superior, em $\mathrm{Kcal} / \mathrm{Kg}$;

$C f=$ Percentagem de carbono fixo;

$V=$ Percentagem de material volátil e

$A=$ Coeficiente dado pela relação $V /(V+C)^{*}$.

\begin{tabular}{ll}
$\boldsymbol{V} /(\boldsymbol{V}+\boldsymbol{C})$ & $\boldsymbol{A}$ \\
\hline$<0,05$ & 150 \\
$0,05-0,099$ & 145 \\
$0,1-0,149$ & 130 \\
$0,15-0,199$ & 117 \\
$0,2-0,249$ & 109 \\
$0,25-0,299$ & 103 \\
$0,3-0,359$ & 96 \\
$0,35-0,399$ & 89 \\
$>0,4$ & 80 \\
-----------------------
\end{tabular}

\section{Análise estatística}

Para a análise dos dados, foi adotado o delineamento experimental inteiramente casualizado, com seis tratamentos e cinco repetições, dentro do esquema fatorial $3 \times 2$, sendo três matérias-primas vegetais e duas temperaturas máximas de destilação seca. A comparação estatística entre as médias dos tratamentos foi efetuada pelo teste de Tukey, a 95\% de probabilidade. Os dados foram processados, utilizando-se o programa estatístico Assistat (2008), versão 7.5 beta.
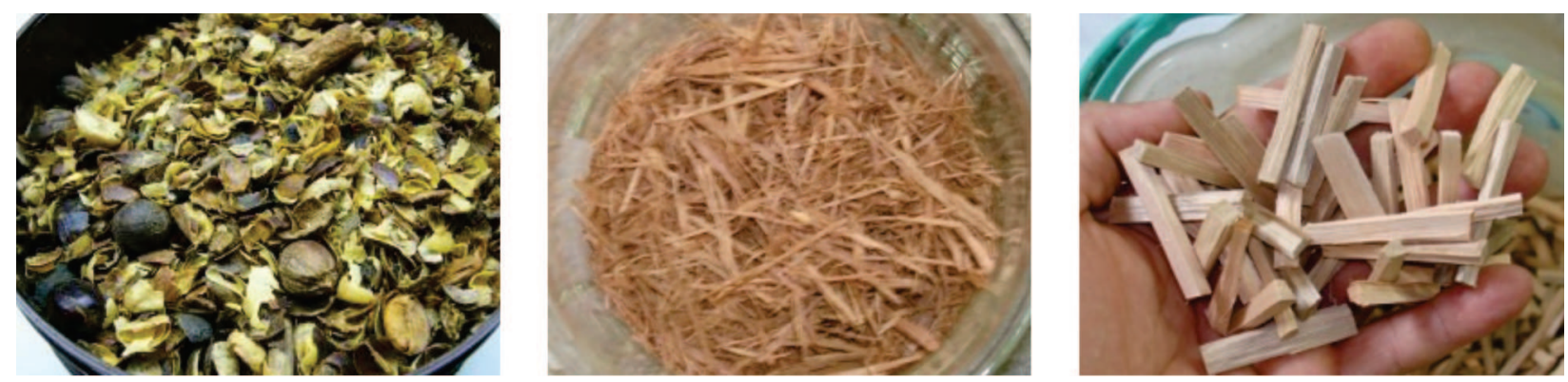

Figura 1. Matérias-primas utilizadas na condução da pesquisa: A. Cascas de grãos de Coffea canephora var. conilon, B. Resíduos da fresa, C. Lenha de Eucalyptus grandis cavaqueada. 


\section{RESULTADOS E DISCUSSÃO}

\section{Rendimentos gravimétricos}

O rendimento gravimétrico em carvão, obtido a partir da lenha de E. grandis foi, em média, menor do que aquele obtido a partir dos resíduos da fresa de madeira e das cascas de café, conforme pode ser observado na Tabela 2.

Para as duas temperaturas máximas de carbonização, todos os rendimentos gravimétricos médios em carvão foram estatisticamente diferentes, sendo que os rendimentos em carvão da casca do café foram os que apresentaram melhores resultados em ambas as temperaturas. A lenha de eucalipto e os resíduos da fresa de madeira a 550 ${ }^{\circ} \mathrm{C}$ apresentaram os menores rendimentos. Houve, para todos os materiais, decréscimo dos respectivos rendimentos gravimétricos em carvão, com o aumento da temperatura de carbonização (Tabela 2). Diversos autores relataram haver uma relação negativa significativa entre o rendimento gravimétrico em carvão e a temperatura máxima de carbonização (Brito, 1990; Andrade, 1993; Nogueira et al., 2000). Dentro de certos limites técnicos e para uma mesma espécie vegetal, quanto maior a temperatura máxima de carbonização menor o rendimento gravimétrico em carvão, como consequência da maior emissão de gases para maiores temperaturas de pirólise, em razão do maior tempo de exposição aos efeitos degradantes da energia térmica. Andrade \& Carvalho (1998) ressaltaram que, com o aumento da temperatura máxima de carbonização, o processo de extração dos compostos volatilizáveis presentes na madeira intensifica-se, quando esta é submetida à ação da energia térmica.
Sob as condições estabelecidas para a destilação seca dos materiais vegetais, foi observado um rendimento em gases condensáveis (líquido pirolenhoso), em média, maior para a lenha de E. grandis, quando comparado com o rendimento das cascas de café e dos resíduos da fresa de madeira. A casca de café foi o resíduo que apresentou o menor valor de líquido pirolenhoso, verificando-se, assim, que os teores de gases condensáveis foram influenciados pelas matérias-primas e não pelas diferentes temperaturas (Tabela 2).

No que se refere ao rendimento em gases não condensáveis, para todos os materiais lignocelulósicos analisados, observou-se um ligeiro aumento no rendimento, com o aumento da temperatura máxima de pirólise. Os maiores valores foram observados nos resíduos da casca de café, pirolisados a $350^{\circ} \mathrm{C}$ e a $550{ }^{\circ} \mathrm{C}$. Os menores valores foram obtidos na destilação da lenha de E. grandis e dos resíduos da fresa de madeira, ambos a $350{ }^{\circ} \mathrm{C}$, respectivamente (Tabela 2). No intervalo de $350{ }^{\circ} \mathrm{Ca} 550^{\circ} \mathrm{C}$, significativas massas de materiais, que ainda se encontravam no interior do carvão, foram forçadas a sair pela ação da energia térmica, elevando o rendimento em gases, o que confirmou a afirmação de Andrade \& Carvalho (1998), de que, dentro de certos limites e para uma mesma espécie vegetal, quanto maior a temperatura máxima de destilação maior será o rendimento em gases não condensáveis.

\section{Análise química}

Em relação aos teores de materiais voláteis foi verificado que quanto maior a temperatura de destilação menor será o seu valor (Tabela 3). Esta afirmativa pode ser

Tabela 1. Tratamentos avaliados no decorrer das análises termogravimétricas das lenhas de Eucalyptus grandis, resíduos da fresa de madeira e de cascas de grãos de café destilados às temperaturas máximas de 350 e $550^{\circ} \mathrm{C}$

\begin{tabular}{ll}
\hline Tratamentos & Especificações \\
\hline 1 & Lenha de $E$. grandis destilada à temperatura máxima de $350{ }^{\circ} \mathrm{C}$ \\
2 & Lenha de $E$. grandis destilada à temperatura máxima de $550^{\circ} \mathrm{C}$ \\
3 & Resíduos da fresa destilados à temperatura máxima de $350{ }^{\circ} \mathrm{C}$ \\
4 & Resíduos da fresa destilados à temperatura máxima de $550^{\circ} \mathrm{C}$ \\
5 & Cascas de grãos de café destiladas à temperatura máxima de $350{ }^{\circ} \mathrm{C}$ \\
6 & Cascas de grãos de café destiladas à temperatura máxima de $550^{\circ} \mathrm{C}$ \\
\hline
\end{tabular}

Tabela 2. Valores médios dos rendimentos gravimétricos em carvão vegetal (RCV), gases condensáveis (RGC) e gases incondensáveis (RGI)

\begin{tabular}{lccccc}
\hline Tratamento & Material lignocelulósico & Temperatura $\left({ }^{\circ} \mathbf{C}\right)$ & RCV $(\%)$ & RGC $(\%)$ & RGI $(\%)$ \\
\hline 1 & \multirow{2}{*}{ Lenha } & 350 & $29,87 \mathrm{~d}$ & $46,62 \mathrm{a}$ & $23,51 \mathrm{c}$ \\
2 & 550 & 350 & $26,08 \mathrm{f}$ & $45,71 \mathrm{ab}$ & $28,21 \mathrm{~b}$ \\
\hline 3 & \multirow{2}{*}{ Resíduos da fresa } & 550 & $27,83 \mathrm{c}$ & $40,60 \mathrm{c}$ & $27,57 \mathrm{bc}$ \\
4 & & 350 & $40,58 \mathrm{a}$ & $27,77 \mathrm{~d}$ & $31,65 \mathrm{ab}$ \\
\hline 5 & \multirow{2}{*}{ Cascas de café } & 550 & $35,40 \mathrm{~b}$ & $29,27 \mathrm{~d}$ & $35,33 \mathrm{a}$ \\
\hline
\end{tabular}

*Nota: Valores médios seguidos de mesma letra na respectiva coluna não diferem estatisticamente entre si, a $95 \%$ de probabilidade, pelo teste de Tukey.

Rev. Ceres, Viçosa, v. 58, n.6, p. 717-722, nov/dez, 2011 
explicada pelo fato de os materiais destilados à temperatura máxima de $550{ }^{\circ} \mathrm{C}$ terem permanecido mais tempo no interior da mufla. De acordo com Andrade \& Carvalho (1998), de forma geral e do ponto de vista estatístico, correlações negativas são observadas entre os teores de materiais voláteis dos carvões e as temperaturas máximas de destilação seca.

Os teores de cinza apresentados pelos carvões derivados da casca do café foram muito altos, quando comparados com os teores de cinza apresentados pelos carvões derivados dos resíduos da fresa de madeira e da lenha de E. grandis (Tabela 3). Segundo Vale et al. (2007), altos teores de cinza provocam reduções nos teores de carbono fixado no carvão vegetal e estão relacionados com a presença de quantidades e de qualidades diferentes de minerais presentes na biomassa, tais como cálcio, potássio, fósforo, magnésio, ferro, sódio, entre outros, que fazem aumentar os teores de cinza.

Em relação aos teores de carbono fixo, os maiores valores foram apresentados pelos carvões destilados a temperaturas máximas de $550^{\circ} \mathrm{C}$, independentemente da matéria prima utilizada (Tabela 3). Confirmou-se, portanto, conforme enunciado por Andrade (1993), Andrade \& Carvalho (1998) e Nogueira et al. (2000), que há uma correlação positiva entre os teores de carbono fixo e as temperaturas máximas de destilação, isto é, quanto maior a temperatura final de destilação, maior será o teor de carbono fixo dos materiais destilados.
O rendimento em carbono fixo, obtido a partir da casca do grão de café foi, em média, maior que aquele obtido a partir do carvão da lenha de E. grandis (Tabela 3). Isto ocorreu em função dos maiores rendimentos gravimétricos em carvão vegetal (RCV) da casca do grão de café, observados no decorrer das destilações (Tabela 2). Andrade (1989) afirmou que o rendimento em carbono fixo é o parâmetro que melhor expressa a qualidade energética da matéria-prima lignocelulósica, para a produção de carvão vegetal. Dessa forma, os resultados evidenciam que o carvão da casca de café destilado em ambas as temperaturas apresentou melhor qualidade, quando comparado com as demais matérias-primas estudadas.

Para Oliveira et al. (1982), os aumentos na temperatura final de carbonização proporcionam aumento no rendimento de carbono fixo e redução no rendimento em carvão.

\section{Estimativa do poder calorífico superior}

Foi possível verificar que houve diferença significativa entre os valores de poder calorífico entre os diferentes tratamentos (Tabela 4). Os maiores valores de poder calorífico superior foram encontrados para a lenha de $E$. grandis, em decorrência dos valores de carbono fixo encontrados, em relação às diferentes matérias-primas estudadas. Esses valores estão de acordo com Tienne et al. (2004), para os quais, o poder calorífico superior (PCS) tem relação direta com o teor de carbono fixo do carvão vegetal.

Tabela 3. Valores médios dos teores de matérias voláteis (TMV), de cinza (TCZ), de carbono fixo (TCF) e rendimento em carbono fixo (RCF) dos carvões dos materiais lignocelulósicos analisados

\begin{tabular}{lcccccc}
\hline Tratamento & Material lignocelulósico & Temperatura $\left({ }^{\circ} \mathbf{C}\right)$ & $\mathbf{T M V}(\%)$ & TCZ $(\%)$ & $\mathbf{T C F}(\%)$ & $\mathbf{R C F}(\%)$ \\
\hline 1 & \multirow{2}{*}{ Lenha } & 350 & $24,76 \mathrm{~b}$ & $00,36 \mathrm{~d}$ & $74,60 \mathrm{c}$ & $22,28 \mathrm{bc}$ \\
2 & 550 & $09,62 \mathrm{~d}$ & $00,62 \mathrm{~d}$ & $90,00 \mathrm{a}$ & $23,47 \mathrm{ab}$ \\
\hline 3 & \multirow{2}{*}{ Resíduos da fresa } & 350 & $28,80 \mathrm{a}$ & $01,92 \mathrm{c}$ & $69,20 \mathrm{~d}$ & $22,02 \mathrm{c}$ \\
4 & & 550 & $10,60 \mathrm{~d}$ & $03,32 \mathrm{~b}$ & $86,20 \mathrm{~b}$ & $23,98 \mathrm{a}$ \\
\hline 5 & \multirow{2}{*}{ Cascas de café } & 350 & $25,80 \mathrm{~b}$ & $14,80 \mathrm{a}$ & $59,40 \mathrm{e}$ & $24,11 \mathrm{a}$ \\
6 & & 550 & $15,00 \mathrm{c}$ & $15,60 \mathrm{a}$ & $69,40 \mathrm{~d}$ & $24,57 \mathrm{a}$ \\
\hline
\end{tabular}

*Nota: Valores médios seguidos de mesma letra na respectiva coluna não diferem estatisticamente entre si, a $95 \%$ de probabilidade, pelo teste de Tukey

Tabela 4. Valores médios do poder calorífico superior (PCS) da lenha de Eucalyptus grandis, das cascas de café (Coffea canephora var. Conilon) e dos resíduos da fresa de madeira

\begin{tabular}{lcccc}
\hline Tratamento & Material lignocelulósico & Temperatura $\left({ }^{\circ} \mathbf{C}\right)$ & TCF $(\%)$ & PCS $(\mathbf{K c a l} / \mathbf{K g})$ \\
\hline 1 & \multirow{2}{*}{ Lenha } & 350 & $74,60 \mathrm{c}$ & $8716,8 \mathrm{a}$ \\
2 & & 550 & $90,00 \mathrm{a}$ & $8622,0 \mathrm{ab}$ \\
\hline 3 & \multirow{2}{*}{ Resíduos da fresa } & 350 & $69,20 \mathrm{~d}$ & $8556,8 \mathrm{ab}$ \\
4 & & 550 & $86,20 \mathrm{~b}$ & $8473,4 \mathrm{~b}$ \\
\hline 5 & \multirow{2}{*}{ Cascas de café } & 350 & $59,40 \mathrm{e}$ & $7417,6 \mathrm{c}$ \\
6 & & 550 & $69,40 \mathrm{~d}$ & $7418,6 \mathrm{c}$ \\
\hline
\end{tabular}

*Nota: Valores médios seguidos de mesma letra na respectiva coluna não diferem estatisticamente entre si, a $95 \%$ de probabilidade, pelo teste de Tukey. 


\section{CONCLUSÕES}

Os resíduos de casca de café proporcionaram boa produção de carvão vegetal, visto que seus rendimentos gravimétricos em carvão foram superiores aos dos demais tratamentos (lenha de Eucalyptus grandis e resíduos da fresa).

Ao visar à qualidade do carvão vegetal sem, contudo, atentar para a produtividade, deve-se optar pelo uso dos resíduos da fresa de madeira, destilados à temperatura máxima de $550{ }^{\circ} \mathrm{C}$, cujo teor médio de carbono fixo foi muito próximo àquele apresentado pelo carvão da lenha de E. grandis, destilado à mesma temperatura.

Ao buscar a produtividade e a qualidade do carvão vegetal, deve-se optar pela casca de café, em ambas as temperaturas $\left(350^{\circ} \mathrm{C}\right.$ e $\left.550{ }^{\circ} \mathrm{C}\right)$, e pelos resíduos da fresa de madeira, destilados a $550{ }^{\circ} \mathrm{C}$, por causa dos rendimentos médios em carbono fixo, que, nesses casos, superaram aqueles apresentados pelos carvões derivados da lenha de E. grandis.

Os resíduos da fresa de madeira poderão ser utilizados para secagem de grãos de café, pois, apresentaram valores de PCS muito próximos aos da lenha de E. grandis.

Em razão dos bons rendimentos gravimétricos e em carbono fixo apresentados, o carvão vegetal derivado dos resíduos estudados mostra grande potencial para ser utilizado como insumo energético na secagem artificial de café.

\section{REFERÊNCIAS}

Afonso Júnior PC, Filho DO \& Costa DR (2006) Viabilidade econômica de produção de lenha de eucalipto para secagem de produtos agrícolas. Engenharia Agrícola, 26:28-35.

Andrade AM (1993) Efeitos da fertilização mineral e da calagem na produção e na qualidade da madeira e do carvão de eucalipto. Tese de Doutorado. Universidade Federal de Viçosa, Viçosa, 105p.

Andrade AM (1989) Influência da casca de Eucalyptus grandis W. Hill ex Maiden no rendimento e qualidade de carvão vegetal. Dissertação de Mestrado. Universidade Federal de Viçosa, Viçosa, $86 \mathrm{p}$.

Andrade AM \& Carvalho LM (1998) Potencialidades energéticas de oito espécies florestais do Estado do Rio de Janeiro. Floresta e Ambiente, 5:24-42.

Assistat - Assistência estatística (2008). Download: versão 7.5 beta. 2008. Disponível em http:<//www.assistat.com>. Acessado em: 16 de novembro de 2008.

Brand MA, Muñiz GIB, Silva DA \& Klock U (2002) Caracterização do rendimento e quantificação dos resíduos gerados em serrarias através do balanço de materiais. Floresta, 32:247-259.

Brito JO (1990) Princípios de produção e utilização de carvão vegetal de madeira. Documentos Florestais, 9:1-19.

Conab (2010) Café Conjuntura no Espírito Santo. Vitória, Espírito Santo/Conab. $12 \mathrm{p}$.

Ferrão RG, Fonseca AFA, Bragança SM, Ferrão MAG \& De Muner LH (2007) Café Conilon. Vitória, Incaper. 702p.
Hall DO (1991) Biomass Energy. Energy Policy, 19:711-737.

Mendes MG, Gomes PA \& Oliveira JB (1982) Propriedades e controle de qualidade do carvão vegetal. In: Penedo WR (Ed.) Carvão Vegetal. Belo Horizonte, CETEC - Centro Tecnológico de Minas Gerais. p.75-90.

Nascimento A (2011) Etanol brasileiro segue como principal alternativa em bioenergia. Disponível em: <http:// euleionn.com.br/noticias/energia-alternativa/etanol-brasileirosegue-como-principal-alternativa-em-bioenergia>. Acessado em: 18 de outubro de 2011.

Nogueira LAH, Lora EES, Trossero MA \& Frisk T (2000) Dendroenergia: fundamentos e aplicações. Brasília, ANEEL Agência Nacional de Energia Elétrica. 144p.

Oliveira JB, Gomes PA \& Almeida MR (1982) Propriedades do carvão vegetal. In: Penedo WR (Ed.) Carvão vegetal. Belo Horizonte, CETEC - Centro Tecnológico de Minas Gerais. p.961.

Quirino WF (2003) Utilização energética de resíduos vegetais. Brasília, Laboratório de Produtos Florestais - LPF/IBAMA. 14p.

Tienne L, Deschamps MC \& Andrade AM (2004) Produção de carvão e subprodutos da pirólise da casca e do bagaço da laranja (Citrus sinensis). Biomassa \& Energia, 1:191-197.

Vale AT, Gentil LV, Gonçalez J C \& Costa AF (2007) Caracterização energética e rendimento da carbonização de resíduos de grãos de café (Coffea arabica L.) e de madeira (Cedrelinga catenaeformis), Duke. Cerne, 13:416-420. 